Revista Brasileira de Agricultura Irrigada v.12, nº.6, p. 2984 - 2990, 2018

ISSN 1982-7679 (On-line)

Fortaleza, CE, INOVAGRI - http://www.inovagri.org.br

DOI: $10.7127 /$ rbai.v12n600828

Protocolo 828.18 - 29/11/2017 Aprovado em 18/12/2018

\title{
CRESCIMENTO E PARTIÇÃO DE MASSA SECA EM MUDAS DE MAMOEIRO SOB ESTRESSE SALINO
}

Lucimara Ferreira de Figueredo ${ }^{1}$, Sebastião de Oliveira Maia Júnior ${ }^{2}$, Rener Luciano de Souza Ferraz ${ }^{3}$, Alexson Filgueiras Dutra ${ }^{4}$, Jeferson Dutra Bezerra ${ }^{1}$, Alberto Soares de Melo ${ }^{5}$

\section{RESUMO}

No Brasil o mamoeiro nas diversas áreas onde é produzido tem grande importância socioeconômica, especificamente na região Nordeste. Contudo, nessa região, a maioria dos reservatórios contém água com elevados teores de sais. Dessa maneira, objetivou-se com este trabalho avaliar o crescimento e a partição de fitomassa seca de mudas de mamoeiro UENF/Caliman 01 irrigado com água salina. $O$ experimento foi realizado em casa de vegetação, no setor de Fruticultura e Ecofisiologia Vegetal da Universidade Estadual da Paraíba, localizado no município de Catolé do Rocha, coordenadas $06^{\circ} 21^{\prime} \mathrm{S}$ e $37^{\circ} 48^{\prime} \mathrm{W}$. Foi utilizado o delineamento experimental inteiramente casualizado, constituído de cinco tratamentos: salinidade da água $\left(0,6 ; 1,2 ; 1,8 ; 2,4\right.$ e $\left.3,0 \mathrm{dS} \mathrm{m} \mathrm{m}^{-1}\right)$ com quatro repetições. $\mathrm{O}$ aumento da salinidade da água reduziu a altura de plantas, diâmetro do caule, área foliar e fitomassa seca das folhas, caule e raiz do mamoeiro UENF/Caliman 01, aos 60 dias após a semeadura. $\mathrm{O}$ diâmetro do caule do mamoeiro UENF/Caliman 01 é uma característica pouco sensível à salinidade da água, ao passo que a área foliar e a fitomassa seca foliar são bastante sensíveis.

Palavras-chave: produção de biomassa, Carica papaya, salinidade.

\section{GROWTH AND PARTITION OF DRY MASS OF PAPAYA SEEDLINGS UNDER SALT STRESS}

\footnotetext{
ABSTRACT

${ }^{1}$ Doutores em Agronomia, Centro de Ciências Agrárias, Universidade Federal da Paraíba, Areia/ PB, Brasil, emails: lucimara.ufpb@gmail.com,jefersondutra_sbpb@hotmail.com

${ }^{2}$ Dr. em Agronomia, Centro de Ciências Agrárias, Universidade Federal de Alagoas, Rio Largo/ AL, Brasil, email: juniormaiagrari@hotmail.com

${ }^{3}$ Dr. em Engenharia Agrícola, Universidade Estadual da Paraíba, Lagoa Seca/ PB, Brasil, e-mail: ferraz340@gmail.com

${ }^{4}$ Dr. em Agronomia, Universidade Estadual de São Paulo, Jaboticabal/SP, Brasil, e-mail: alexsonbrejo@hotmail.com

${ }^{5}$ Prof. Dr., Universidade Estadual da Paraíba, Campina Grande/PB, Brasil, e-mail: alberto@uepb.edu.br
} 
In Brazil the papaya in the different areas where it is produced has great socioeconomic importance, specifically in the Northeast region. However, in this region, most reservoirs contain water with high salt content. In this way, the objective of this work was to evaluate the growth and partition of dry phytomass of UENF/Caliman 01 papaya seedlings irrigated with saline water. The experiment was conducted in a greenhouse of the State University of Paraíba, located in the city of Catolé do Rocha, coordinated $06^{\circ} 21^{\prime} \mathrm{S}$ e $37^{\circ} 48^{\prime} \mathrm{W}$. The experimental design was completely randomized, consisting of five treatments: water salinity $(0.6,1.2,1.8$, 2.4 and $3.0 \mathrm{dS} \mathrm{m}-1$ ) with four replicates. The increase of water salinity reduced plant height, stem diameter, leaf area and dry matter of leaves, stem and root of UENF/Caliman 01 papaya, at 60 days after seeding. The stem diameter of papaya UENF/Caliman 01 is a characteristic little sensitive to water salinity, while the leaf area and leaf dry weight are very sensitive.

Keywords: biomass production, Carica papaya, salinity.

\section{INTRODUÇÃO}

A produção de frutíferas, no Brasil, chegou em 2016 a ganhos de produção de $\mathrm{R}$ \$33,3 bilhões, com um acréscimo de $26 \%$ em relação ao ano de 2015, sendo que detses o mamão representou $4,4 \%$ (IBGE, 2016).

O mamoeiro (Carica papaya L.) é uma planta de porte herbáceo, de clima tropical e subtropical, com grande importância econômica no Brasil, pois é uma cultura que gera milhares de emprego, desde a produção de mudas até a implantação e/ou renovação dos pomares. No entanto, alguns cuidados devem ser tomados, principalmente, na fase de produção das mudas quanto à qualidade da água usada na irrigação (MESQUITA et al., 2012; SÁ et al., 2013).

O manejo hídrico na cultura do mamoeiro tem se tornado um fator cada vez mais importante e delicado, uma vez que a escassez de água vem sendo um problema frequentemente relatado, requerendo boas estratégias para o manejo da cultura. $\mathrm{O}$ mamoeiro tem se expandido em diferentes polos frutícolas brasileiros, abrangendo inúmeras áreas localizadas no Nordeste brasileiro, além do norte de Minas Gerais (SANTOS et al., 2015). Contudo, especificamente nessas áreas semiáridas do Brasil, as águas utilizadas nas irrigações, quase sempre, possuem elevadas concentrações de sais que podem comprometer o solo e principalmente o desenvolvimento das culturas, sendo mais intenso na fase inicial da grande maioria das fruteiras (SÁ et al., 2013; MOURA et al., 2017; SILVA et al., 2017).

A redução no crescimento e no desenvolvimento acarretada pela utilização de águas salinas é bastante relatada em diversos estudos envolvendo fruteiras, como em goiabeira (SILVA et al., 2017), maracujazeiro (OLIVEIRA et al., 2015), cajueiro (SOUSA et al., 2011), bem como mamoeiro (SÁ et al., 2013). No entanto, o efeito da salinidade da água é variável entre espécies, entre genótipos de uma mesma espécie e entre fases de desenvolvimento (AYERS; WESTCOT, 1999), o que pode acontecer com novos materiais como é o caso do híbrido de mamoeiro UENF/Caliman 01.

A cultura do mamoeiro é considerada moderadamente tolerante à salinidade, chegando a tolerar níveis de salinidade de até $6 \mathrm{dS} \mathrm{m} \mathrm{m}^{-1}$ sem comprometer o crescimento e desenvolvimento (AYERS; WESTCOT, 1999). Todavia, há uma grande variabilidade entre materiais de uma mesma espécie, além da fase de desenvolvimento quanto à tolerância à salinidade (SOUSA et al., 2011; MESQUITA et al., 2012). Dessa maneira, a identificação de materiais tolerantes pode ser uma alternativa para o uso de águas salinas, aumentando a disponibilidade hídrica e a eficiência desse recurso na região semiárida.

Nesse contexto, objetivou-se com este trabalho avaliar o crescimento e a partição de fitomassa seca de mudas de mamoeiro híbrido UENF/Caliman 01 irrigado com água de diferentes concentrações salinas.

\section{MATERIAL E MÉTODOS}

O experimento foi realizado em casa de vegetação, no setor de Fruticultura e Ecofisiologia Vegetal do Departamento de Ciências Agrárias, 
Câmpus IV, da Universidade Estadual da Paraíba, localizado no município de Catolé do Rocha, PB.O local tem altitude de 250 metros e está situado a $06^{\circ} 21^{\prime} \mathrm{S}$ e $37^{\circ} 48^{\prime} \mathrm{W}$. O clima da região, segundo classificação de Koppen, é do tipo BSw'h', semiárido quente, com duas estações bem distintas, uma seca e uma chuvosa com precipitação irregular, com precipitação média anual de 870 $\mathrm{mm}$, temperatura média de $27^{\circ} \mathrm{C}$, e período chuvoso concentrado entre os meses de fevereiro e abril.

A semeadura foi realizada em sacos polietileno com capacidade de $300 \mathrm{~mL}$ contendo substrato comercial composto de vermicultura, casca de pinus e casca de arroz carbonizada, na proporção de 1:1:1. Foram semeadas em cada saco, três sementes do híbrido UENF/Caliman 01 obtido por cruzamento de um progenitor do grupo Formosa e um progenitor do grupo Solo. As sementes foram cedidas pela Universidade Estadual Norte Fluminense. Quando as plantas se encontravam com duas folhas definitivas foi feito o desbaste mantendo-se apenas uma planta em cada recipiente.

O delineamento experimental foi $o$ inteiramente casualizado, com cinco níveis de salinidade da água: 0,$6 ; 1,2 ; 1,8 ; 2,4$ e $3,0 \mathrm{dS} \mathrm{m}{ }^{-1}$, com quatro repetições, e quatro plantas por cada repetição.

As águas com as diferentes concentrações salinas utilizadas na irrigação, foram preparadas de modo a se ter uma proporção de 7:2:1 entre $\mathrm{Na}$ : $\mathrm{Ca}$ : $\mathrm{Mg}$, respectivamente, a partir dos sais $\mathrm{NaCl}$, $\mathrm{CaCl}_{2} .2\left(\mathrm{H}_{2} \mathrm{O}\right)$ e $\mathrm{MgCl}_{2} .6\left(\mathrm{H}_{2} \mathrm{O}\right)$, relação essa predominante em fontes de água utilizada para irrigação, em pequenas propriedades do Nordeste (AUDRY; SUASSUNA, 1995; MEDEIROS, 1992).

Na preparação das águas de irrigação foram consideradas a relação $\mathrm{CEa}$ e concentração de sais, válida para $\mathrm{CEa}$ de 0,1 a $5,0 \mathrm{dS} \mathrm{m}{ }^{-1}$ em que se enquadra os cinco níveis analisados, tendo como base a água de abastecimento existente no local. Após a preparação, as águas foram armazenadas em vasos de $30 \mathrm{~L}$, cada um com um nível de salinidade, devidamente tampados e identificados.

$$
\text { A irrigação era realizada ao final }
$$

do dia repondo a água perdida por evapotranspiração, calculando a ETo, baseada na evaporação de um tanque classe " $A$ " instalado no interior da casa de vegetação.
A ETo foi calculada, como:

$$
\mathrm{ETo}=\mathrm{ECA} * \mathrm{Kp}
$$

Em que:

$\mathrm{ETo}=$ evapotranspiração baseada no tanque classe A em mm dia ${ }^{-1}$;

$\mathrm{ECA}=$ evaporação do tanque;

$\mathrm{Kp}=$ fator de correção do tanque. Foi adotado o $\mathrm{K} p=1,0$ (FERNANDES et al., 2004).

Posteriormente, foi calculada a ETc, levando-se em consideração o coeficiente da cultura na fase de formação das mudas. Durante todo o experimento, fase de mudas, foi utilizado $\mathrm{Kc}=0,60$.

Para tanto, a ETc foi calculada, como:

$$
\mathrm{ETc}=\mathrm{ETo} * \mathrm{Kc}
$$

Em que:

ETc = Evapotranspiração da cultura;

ETo = evapotranspiração baseada no tanque classe A em mm dia ${ }^{-1}$;

$\mathrm{Kc}=$ coeficiente da cultura.

Durante os dez primeiros dias se utilizou apenas água de $0,6 \mathrm{dS} \mathrm{m}^{-1} \mathrm{e}$, a partir do décimo primeiro dia iniciaram-se os tratamentos, irrigando cada um com a água de salinidade correspondente.

Aos 60 dias após a semeadura (50 dias após início dos tratamentos), foram avaliadas a altura de plantas, diâmetro caulinar, área foliar e partição de fitomassa seca das plantas.

A altura de planta (AP) foi determinada utilizando-se régua graduada em centímetro tomando como referência, a distância do colo ao ápice da planta. O diâmetro caulinar (DC) foi quantificado utilizando-se um paquímetro analógico.

A área foliar foi determinada medindo-se o comprimento dos lóbulos centrais de todas as folhas da planta, conforme Alves e Santos (2002), como:

$$
\mathrm{AF}=0,0859 \mathrm{~L}^{\wedge} 2,7835
$$

Em que:

$\mathrm{AF}=$ área foliar $\left(\mathrm{cm}^{2}\right)$;

$\mathrm{L}=$ comprimento do lóbulo central $(\mathrm{cm})$.

A partição de fitomassa seca foi realizada após a coleta das plantas com a separação das diferentes partes: folhas, caules e raízes, as quais 
foram colocadas em estufa de circulação de ar a $60^{\circ}$ $\mathrm{C}$, até atingirem massa constante.

Os dados foram submetidos a analise de variância pelo teste $\mathrm{F}(\mathrm{p}<0,05)$ e os modelos de regressão ajustados de acordo com o coeficiente de determinação até 5\% de significância (STORCK et. al., 2000), utilizando os programas SAEG 9.0 e Table Curve 2D.

\section{RESULTADOS E DISCUSSÃO}

O aumento da salinidade da água de irrigação proporcionou redução na altura das mudas de mamoeiro, ao passo que com o aumento unitário da

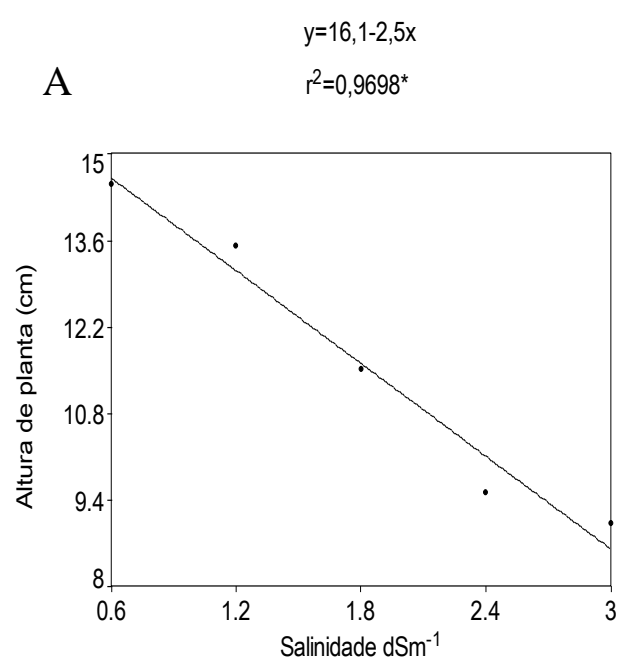

$\mathrm{CEa}\left(\mathrm{dS} \mathrm{m}^{-1}\right)$ houve uma redução na área foliar de $17,1 \%$, chegando a uma redução de $41,1 \%$ entre o menor e o maior nível de salinidade (Figura 1A).

Do mesmo modo, a salinidade também reduziu o diâmetro caulinar, aproximadamente 10

$\%$, entre o menor e o maior nível de salinidade (Figura 1B).

A área foliar também reduziu à medida que se aumentou a salinidade da água, ao passo que com o aumento unitário da $\mathrm{CEa}$ (dS $\mathrm{m}^{-1}$ ) a área foliar reduziu $14,2 \%$, chegando a uma redução de $33,2 \%$ entre o menore o maior nível de salinidade (Figura 1C).

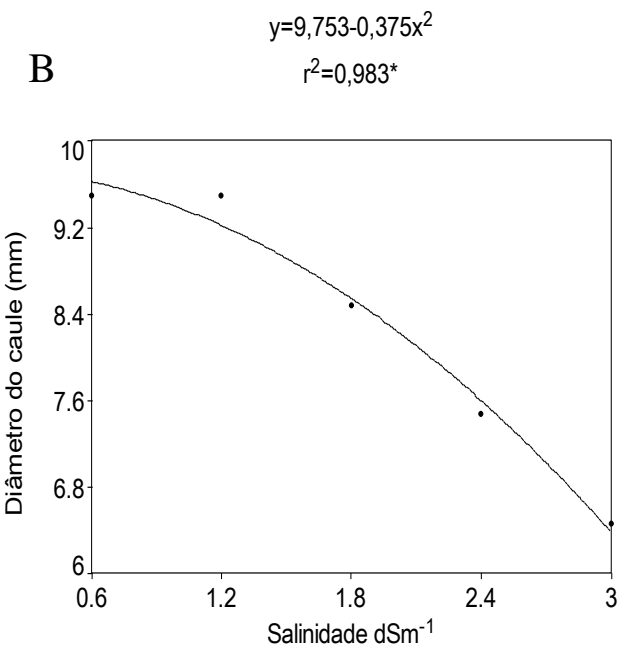

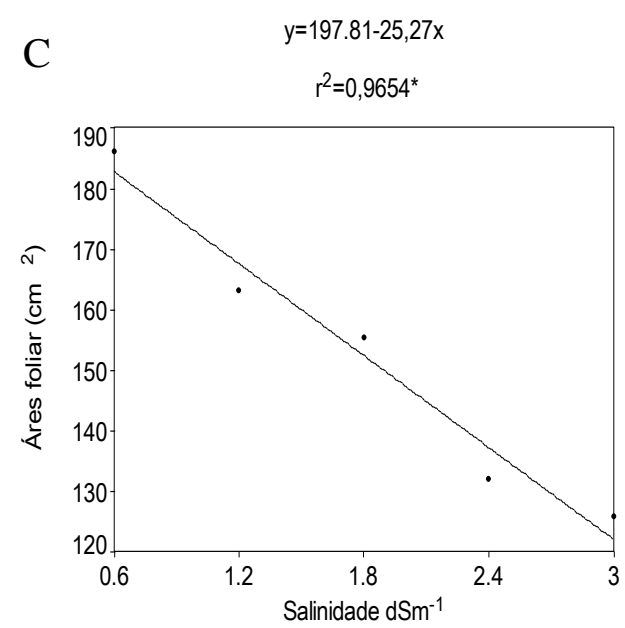

Figura 1. Altura de plantas (A), diâmetro do caule (B) e área foliar (C) de mudas de mamoeiro híbrido UENF/Caliman 01 cultivadas em tubetes e submetidas a diferentes salinidades da água de irrigação $\left(\mathrm{dSm}^{-1}\right)$.

O crescimento das plantas geralmente é reduzido com o aumento da salinidade da água, principalmente na fase de mudas (OLIVEIRA et al., 2015; SILVA et al., 2017). Além disso, uma maior redução é observada no crescimento em altura e expansão foliar, em relação ao diâmetro do caule. Resultados semelhantes foram constatados por Oliveira et al. (2015) que avaliando mudas de 
maracujazeiro amarelo, encontraram redução de 37,0 e $13,8 \%$ para a altura de planta e o diâmetro do caule, respectivamente, comparando-se as plantas sob menor salinidade da água $\left(0,3 \mathrm{dS} \mathrm{m}^{-1}\right)$ em relação a maior $\left(3,5 \mathrm{dS} \mathrm{m}^{-1}\right)$.

Do mesmo modo, maior redução no crescimento em altura que no diâmetro do caule pela salinidade da água também foi verificado em mudas das cultivares de mamoeiro Sunrise Solo e Tainung1 (SÁ et al., 2013). O fato de o caule das mudas do mamoeiro UENF/Caliman 01 ter baixa redução até a salinidade da água de $3,0 \mathrm{dS} \mathrm{m} \mathrm{m}^{-1}$, sugere que as mudas possuem maior qualidade e resistência para serem introduzidas em campo como reportado por Sá et al. (2013), também em mudas de mamoeiro.

As maiores reduções na altura e área foliar podem ser devido ao acúmulo de sais no substrato. O uso progressivo de água salina na irrigação proporciona o acúmulo de sais nas camadas superficiais do solo, sendo proporcional à concentração de sais da água (MEDEIROS et al., 2017). Dessa maneira, o aumento da salinidade reduz o potencial osmótico do substrato, e maior concentração de sais no substrato exerce efeito de fitotoxicidade nas plantas desencadeando um conjunto de alterações iônicas e hormonais afetando diretamente o crescimento destas (SÁ et al., 2013; OLIVEIRA et al., 2015). Esses efeitos prejudiciais no crescimento são, principalmente, causados pelos íons $\mathrm{Na}^{+}$e $\mathrm{Cl}^{-}$, como constatado por Silva et al. (2011). Esses autores observaram em plantas de pinhão-manso, após 14 dias expostas ao estresse salino, que as concentrações de $\mathrm{Na}^{+} \mathrm{e} \mathrm{Cl}^{-}$ atingiram níveis muito altos, possivelmente alcançando valores tóxicos.

Nesse sentido, o decréscimo da área foliar, possivelmente está relacionado aos mecanismos de adaptação da planta ao estresse salino, como a diminuição da superfície transpirante (SILVA et al., 2009). Além disso, a redução da área foliar pode ocorrer devido a menor expansão das folhas ocasionada pelo maior acúmulo de sais ou pela senescência para exclusão dos sais acumulados (SILVA et al., 2017), resultando em menor área foliar, como observado nas mudas do mamoeiro UENF/Caliman 01 quando submetido a salinidade da água de 3,0 $\mathrm{dS} \mathrm{m}{ }^{-1}$. Sá et al. (2013) também observaram que a área foliar, entre as variáveis de crescimento, foi a mais afetada pelo aumento da salinidade da água de irrigação, atribuindo tanto à redução na expansão foliar quanto à diminuição na formação de folhas pelo estresse salino.

A fitomassa seca foliar decresceu à medida que se aumentou a salinidade da água de irrigação. Esse decréscimo na massa seca foliar chegou a $119 \%$ entre o menor e o maior nível de salinidade da água (Figura 2A).

A fitomassa seca caulinar também decresceu à medida que se aumentou a salinidade da água de irrigação, de modo que com o aumento unitário da CEa $\left(\mathrm{dS} \mathrm{m}^{-1}\right)$ houve uma redução na fitomassa caulinar de $10,6 \%$, chegando esse decréscimo a $40 \%$ entre o menor e o maior nível de salinidade (Figura 2B). De maneira semelhante, a fitomassa seca da raiz decresceu com o aumento da salinidade da água, chegando a uma redução de $102 \%$ entre o menor e o maior nível de salinidade (Figura 2C).

As reduções ocasionadas no crescimento das plantas pela salinidade refletem na produção de fitomassa seca, como observado em mudas de goiabeira (SILVA et al., 2017), maracujazeiro (OLIVEIRA et al., 2015) e mamoeiro (SÁ et al., 2013) 

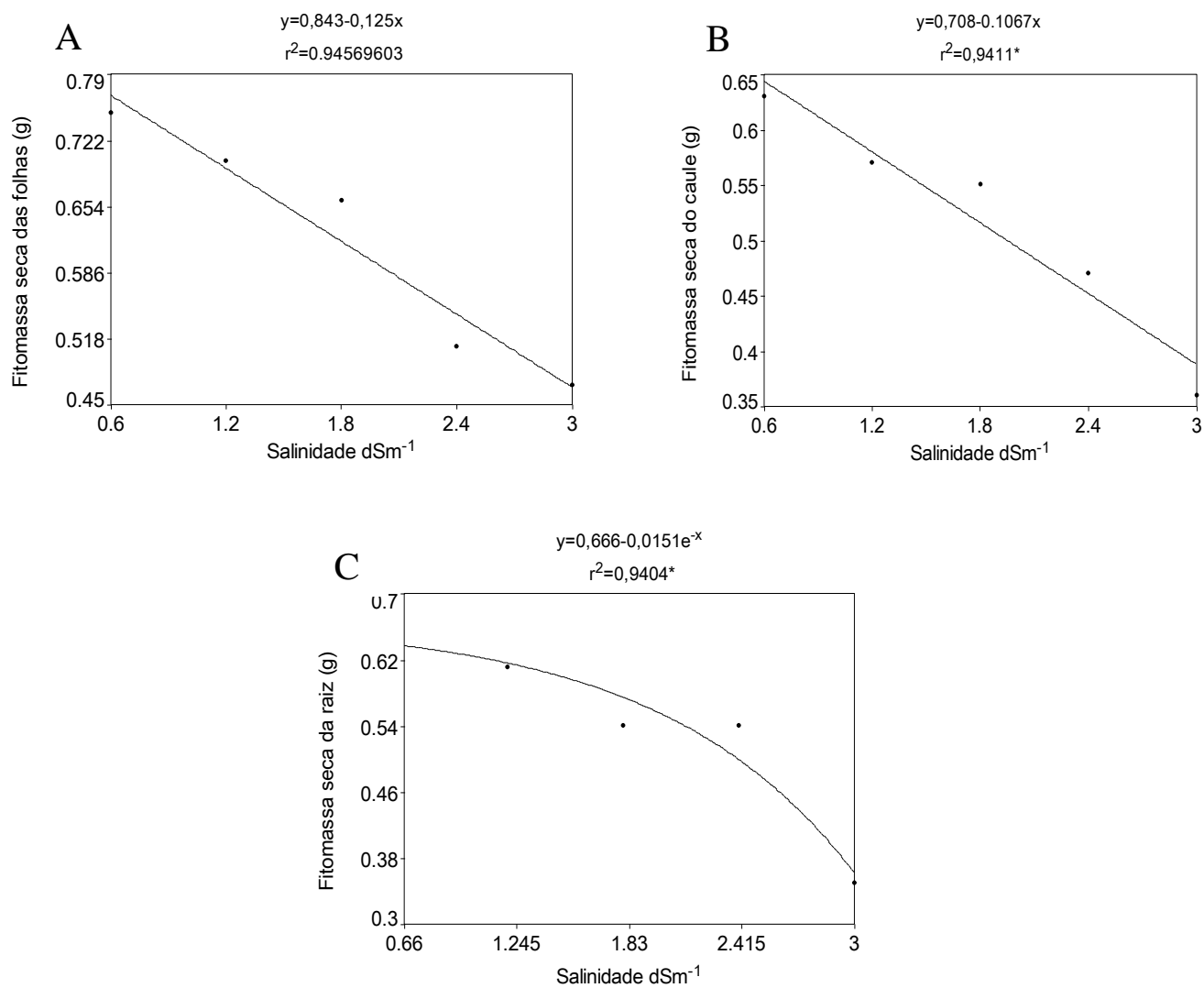

Figura 2. Fitomassa seca das folhas, caule e raiz de mudas de mamoeiro híbrido UENF/Caliman 01 cultivadas em tubetes e submetidas a diferentes salinidades da água de irrigação $\left(\mathrm{dSm}^{-1}\right)$.

A redução na fitomassa seca da raiz é, provavelmente, ocasionada pela restrição no alongamento das raízes, e pode estar relacionada ao mecanismo de tolerância do genótipo, de modo a reduzir a absorção de água e consequentemente de sais, amenizando a toxicidade por íons específicos (SILVA et al., 2011; MOURA et al., 2017). A redução do consumo de água contribui na diminuição da capacidade de produção de fotoassimilados, resultando em menor crescimento como altura, diâmetro e área foliar das plantas, como encontrado em mudas de maracujazeiro (MOURA et al., 2017).

Desta maneira, a água salina afetou $\mathrm{o}$ crescimento das diferentes partes das mudas do mamoeiro UENF/Caliman 01, nesse estudo, que reduziu a fitomassa seca das folhas e do caule.

A redução tanto na fitomassa do caule quanto das folhas está associada à redução ocorrida no crescimento destes órgãos, mais pronunciado nas folhas. Resultados semelhantes foram observados por Sá et al. (2013), ao avaliarem o crescimento de mudas de mamoeiro Sunrise Solo e Tainung1 em função do aumento da salinidade da água de irrigação.

\section{CONCLUSÕES}

Aos 60 dias após a semeadura, o aumento da salinidade da água provoca diminuição do crescimento e partição de fitomassa seca em mudas do mamoeiro híbrido UENF/Caliman 01 cultivadas em tubetes.

O diâmetro do caule de mudas do mamoeiro UENF/Caliman 01 é uma característica pouco sensível à salinidade da água, ao passo que a área foliar e a fitomassa seca foliar são bastante sensíveis.

\section{REFERÊNCIAS}

AUDRY, P.; SUASSUNA, J. A. A qualidade da água na irrigação do trópico semi-árido um estudo de caso. In: Seminário Franco-Brasileiro de Pequena Irrigação. Recife. Anais... Recife: CNPq, SUDENE, 1995. p. 147-153. 
ALVES, A. A.; SANTOS, E. L. Estimativa da área foliar do mamoeiro utilizando medidas da folha. In: CONGRESSO BRASILEIRO DE FRUTICULTURA; 17, 2002, Belém. Anais... Sociedade Brasileira de Fruticultura, 2002.

AYERS, R. S.; WESTCOT, D. W. A qualidade da água para irrigação. Campina Grande: UFPB, 1999. 153p.

FERNANDES, C.; CORÁ, J. E.; ARAÚJO, J. A. C. Utilização do tanque classe "A" para a estimativa da evapotranspiração de referência dentro da casa de vegetação. Engenharia Agrícola, v.24, p.46-50, 2004.

IBGE - Instituo Brasileiro de Geografia e Estatística. Sidra - Produção Agrícola Municipal, $2016 . \quad$ https://agenciadenoticias.ibge.gov.br. Acessado em Nov. 2017.

MEDEIROS, J. F. Qualidade da água de irrigação e evolução da salinidade nas propriedades assistidas pelo 'GAT' nos estados do RN, PB e CE. 1992. 137f. Dissertação (Mestrado em Irrigação e Drenagem). Curso de pós-graduação em Engenharia Agrícola, Universidade Federal de Campina Grande.

MEDEIROS, J. F., NETO, C. P. C. T., SILVA DIAS, N., GHEYI, H. R., SILVA, M. V. T., LOIOLA, A. T. Salinidade e pH de um argissolo irrigado com água salina sob estratégias de manejo. Revista Brasileira de Agricultura Irrigada, v. 11, n. 3, p. 1407-1419, 2017.

MESQUITA, F. O.; RODRIGUES, R. M; MEDEIROS, R. F.; CAVALCANTE, L. F.; BATISTA, R. O. Crescimento inicial de Carica papaya sob irrigação com águas salinas em solo com biofertilizante bovino. Semina: Ciências Agrárias, v. 33, p. 2689-2704, 2012.

MOURA, R. D. S., GHEYI, H. R., COELHO FILHO, M. A., JESUS, O. N., LIMA, L. K. S., CRUZ, C. S. Formation of seedlings of species from the genus passiflora under saline stress. Bioscience Journal, v. 33, n. 5, p. 1197-1207, 2017.
OLIVEIRA, F. A., LOPES, M. A. C., SÁ, F. V. S., NOBRE, R. G., MOREIRA, R. C. L. PAIVA, E. P. Interação salinidade da água de irrigação e substratos na produção de mudas de maracujazeiro amarelo. Comunicata Scientiae, v. 6, n. 4, p. 471478, 2015.

SÁ, F. V. S., BRITO, M. E., MELO, A. S., ANTÔNIO NETO, P., FERNANDES, P. D., FERREIRA, I. B. Produção de mudas de mamoeiro irrigadas com água salina. Revista Brasileira de Engenharia Agrícola e Ambiental, v. 17, n. 10, p. 1047-1054, 2013.

SANTOS, D. B., COELHO, E. F., SIMÕES, W. L., SANTOS JÚNIOR, J. A., COELHO FILHO, M. A., BATISTA, R. O. Influência do balanço de sais sobre o crescimento inicial e aspectos fisiológicos de mamoeiro. Magistra, v. 27, n. 1, p. 44-53, 2015.

SILVA, E. M., NOBRE, R. G., SOUZA, L. P., ARAÚJO, R. H. C. R., PINHEIRO, F. W. A., ALMEIDA, L. L. S. Morfofisiologia de portaenxerto de goiabeira irrigado com águas salinizadas sob doses de nitrogênio. Comunicata Scientiae, v. 8, n. 1, p. 32-42, 2017.

SILVA, E. N. D., RIBEIRO, R. V., FERREIRA-SILVA, S. L., VIÉGAS, R. A., SILVEIRA, J. A. G. Salt stress induced damages on the photosynthesis of physic nut young plants. Scientia Agricola, v. 68, n. 1, p. 62-68, 2011.

SILVA, F. E. O.; MARACAJÁ, P. B.; MEDEIROS, J. F.; OLIVEIRA, F. A.; OLIVEIRA, M. K. T. Desenvolvimento vegetativo do feijãocaupi irrigado com água salina em casa de vegetação. Caatinga, v.22, n.3, p.156-159, 2009.

SOUSA, A. B. O.; BEZERRA, M. A.; FARIAS, F. C. Germinação e desenvolvimento inicial de clones de cajueiro comum sob irrigação com água salina. Revista Brasileira de Engenharia Agrícola e Ambiental, v.15, p. 390394, 2011.

STORCK, GARCIA, D. C.; LOPES, S. J.; ESTEFANEL,V. Experimentação agrícola. Santa Maria : Editora da UFSM, 2000.198p. 